\title{
Inhibition of the AKT/mTOR and erbB pathways by gefitinib, perifosine and analogs of gonadotropin-releasing hormone I and II to overcome tamoxifen resistance in breast cancer cells
}

\author{
MARTIN BLOCK ${ }^{1}$, CARSTEN GRÜNDKER ${ }^{1}$, STEFANIE FISTER ${ }^{1}$, JULIA KUBIN ${ }^{1}$, LUDWIG WILKENS ${ }^{2}$, \\ MICHAEL D. MUELLER ${ }^{3}$, BERNHARD HEMMERLEIN ${ }^{4}$, GÜNTER EMONS ${ }^{1}$ and ANDREAS R. GÜNTHERT ${ }^{1,3}$ \\ ${ }^{1}$ Departement of Gynecology and Obstetrics, Georg-August-University, Göttingen, Germany; ${ }^{2}$ Institute of Pathology, \\ University of Bern; ${ }^{3}$ Department of Gynecology and Obstetrics, Inselspital, Bern University Hospital and \\ University of Bern, Bern, Switzerland; ${ }^{4}$ Institute of Pathology, Georg-August-University, Göttingen, Germany
}

Received May 23,2012; Accepted July 3, 2012

DOI: 10.3892/ijo.2012.1591

\begin{abstract}
Endocrine resistance in breast cancer remains a major clinical problem and is caused by crosstalk mechanisms of growth factor receptor cascades, such as the erbB and $\mathrm{PI} 3 \mathrm{~K} / \mathrm{AKT}$ pathways. The possibilities a single breast cancer cell has to achieve resistance are manifold. We developed a model of 4-hydroxy-tamoxifen (OHT)-resistant human breast cancer cell lines and compared their different expression patterns, activation of growth factor receptor pathways and compared cells by genomic hybridization (CGH). We also tested a panel of selective inhibitors of the erbB and AKT/mTOR pathways to overcome OHT resistance. OHT-resistant MCF-7-TR and T47D-TR cells showed increased expression of HER 2 and activation of AKT. T47D-TR cells showed EGFR expression and activated MAPK (ERK-1/2), whereas in resistant MCF-7-TR cells activated AKT was due to loss of CTMP expression. CGH analyses revealed remarkable aberrations in resistant sublines, which were predominantly depletions. Gefitinib inhibited erbB signalling and restored OHT sensitivity in T47D-TR cells. The AKT inhibitor perifosine restored OHT sensitivity in MCF-7-TR cells. All cell lines showed expression of receptors for gonadotropinreleasing hormone (GnRH) I and II, and analogs of GnRH-I/II
\end{abstract}

Correspondence to: Dr Andreas R. Günthert, University Hospital, Obstetrics and Gynecology, Effingerstr. 102, 3010 Bern, Switzerland E-mail: andreas.guenthert@insel.ch

Abbreviations: AIB1, amplified in beast cancer-1; CTMP, carboxyterminal modulator protein; EGFR, epidermal growth factor receptor; ER, estrogen receptor; ERE, estrogen responsive elements; ERK, extraregulated kinase; $\mathrm{GnRH}$, gonadotropin-releasing hormone; GPR30, G-protein coupled receptor 30; IGF, insulin-like growth factor; mTOR, mammalian target of rapamycin; MAPK, mitogen-activated protein kinase; OHT, 4-hydroxy-tamoxifen; PAX2, paired box 2 gene product; PI3K, phosphitdyl-inositole-3-kinase; SERM, selective estrogen receptor

Key words: breast cancer, gefitinib, GnRH, perifosine, tamoxifen restored OHT sensitivity in both resistant cell lines by inhibition of erbB and AKT signalling. In conclusion, mechanisms to escape endocrine treatment in breast cancer share similarities in expression profiling but are based on substantially different genetic aberrations. Evaluation of activated mediators of growth factor receptor cascades is helpful to predict response to specific inhibitors. Expression of GnRH-I/II receptors provides multitargeting treatment strategies.

\section{Introduction}

Breast cancer is currently seen as a molecularly heterogeneous disease including at least five subtypes, which are defined by gene expression patterns (1). Among these subtypes luminal A and luminal B cancers are defined by an estrogen receptor (ER) positive phenotype and are more differentiated than the HER2 phenotype. Luminal B and HER2 cancer cells show increased proliferation and are believed to have a higher potential for drug resistance, both contributing to a more aggressive behavior (2). The most investigated targeted therapy is the selective estrogen receptor modulator (SERM) tamoxifen. For ER-positive disease only, 5 years of adjuvant tamoxifen reduces the annual breast cancer death rate by $31 \%$. However, the majority of patients show recurrent disease during treatment, which indicates a primary or secondary tamoxifen resistance in more than $50 \%$ of treated patients (3). One factor leading to resistance may be the presentation of breast cancer as heterogeneous tumor manifestation, as for example approximately one third of initially ER-positive breast tumors develop ER-negative lymph node metastases (4). In addition, it has been shown that therapy response to tamoxifen is also negatively affected by overexpression of HER2, co-expression of the ER modulator Amplified In Breast Cancer-1 (AIB1), and the epidermal growth factor receptor (EGFR) (5-7). At the transcriptional level, the paired box 2 gene product (PAX2), which competes with AIB1 for binding and regulation of HER2 transcription, when in complex with ER $\alpha$ is a crucial mediator of ER mediated repression of HER2 by tamoxifen (8). Thus, presence or absence of PAX2 links the luminal with the HER2 dominated subtypes of breast cancer, and decreased expression of PAX2 
predicts tamoxifen-resistance and a worse clinical outcome (8). In fact, tamoxifen acts as an agonist and was shown to be equally effective at regulating genes at the $\operatorname{ER} \alpha$ and $\operatorname{ER} \beta$ (9). In tamoxifen-treated patients, the nuclear co-activator AIB1 acts as a marker of disease relapse by reducing the antagonistic activity of tamoxifen-bound $\mathrm{ER} \alpha$, whereas in untreated patients AIB1 overexpression is associated with decreased risk of relapse $(5,10)$. Besides altered nuclear co-activator expression and overexpression of HER 2 and EGFR, activation of AKT was also shown to predict a worse outcome in tamoxifentreated patients (11). Approximately $19 \%$ of tamoxifen-resistant tumors showed increased HER2 expression and 79\% showed downregulation of ER expression compared to individual primary tumors (12). Additionally to the available clinical data allowing different hypotheses of tamoxifen-resistance, various models of secondary resistant breast cancer cell lines after long-term drug exposure have been developed. Many of these models demonstrated a cross-talk mechanism between the erbB- and the AKT/mammalian target of rapamycin (mTOR) pathways as essential step in endocrine resistance (12-15). In breast cancer, cells developed to be resistant to tamoxifen or fulvestrant, antiestrogen sensitivity could be restored by co-treatment with inhibitors of the erbB-pathway such as trastuzumab, lapatinib or gefitinib, and resistance was due to erbB mediated non-genomic activation of estrogen responsive elements (EREs) in these models (12-14). In our previously presented model of 4OH-tamoxifen (OHT)-resistant MCF7-TR and T47D-TR cells we demonstrated expression of receptors for Gonadotropin-Releasing Hormone (GnRH) I and GnRH-II in parental and resistant sublines, and OHT sensitivity could be restored by pretreatment with analogs of GnRH-I/II (16). In comparison to parental cells, expression analysis in the sublines showed increased HER 2 expression and resistant cells remained ER $\alpha / \beta$ positive. Tumor cell analogs of GnRH-I and GnRH-II inhibited mitogenic signal transduction of growth factor receptors via activation of a phosphotyrosine phosphatase, and blocked the autophosphorylation of the EGFR and activation of mitogen-activated protein kinase (MAPK, ERK-1/2), resulting in downregulation of cancer cell proliferation (16-19). In addition, GnRH-I inhibited AKT activation and induced apoptosis in prostate cancer cells (20). The insulin-like growth factor (IGFR) I receptor/phosphatidyl-inositol-3-kinase (PI3K)/AKT/mTOR pathway has also been subject of intensive research in the field of antiestrogen resistance $(21,22)$. To summarize the consistent findings of the cited studies, the IGFR/PI3K/AKT/mTOR pathway communicates synergistically with the erbB signal transduction through activation of AKT and MAPK (ERK-1/2), especially in cells overexpressing HER2. Specific inhibitors of MAPK, IGFR or mTOR increased the antiproliferative effects of antiestrogens and restored antiestrogen sensitivity $(21,22)$. Besides the increased activation of AKT associated with HER2 overexpression, AKT activation is found in cells with mutated tumor suppressor gene PTEN, and its activation is negatively regulated by the carboxyterminal modulator protein (CTMP) $(13,23,24)$. In addition, the $\mathrm{PI} 3 \mathrm{~K} / \mathrm{AKT} / \mathrm{mTOR}$ pathway can also be activated by intrinsic activation of the membrane bound ER GPR30 (25).

The aim of this study was to analyze the expression of mediators of growth factor receptor pathways focusing on HER2/EGFR/MAPK/AIB-1, IGFR/PI3K/AKT/mTOR, and the autocrine non-ER-mediated estrogen dependent cell growth via aromatase and GPR30 expression in our previously described model of OHT-resistant breast cancer cells (16). We tried to define the essential mediators required to restore $\mathrm{OHT}$ sensitivity by testing a panel of specific inhibitors of erbB and AKT/mTOR signalling in combination with OHT. Since our in vitro model identified analogs of GnRH-I/II as effective drugs to restore antiestrogen sensitivity, we defined their potential clinical relevance by comparing the expression of receptors for GnRH-I and GnRH-II with expression of ER and HER2 in 100 breast cancers.

\section{Materials and methods}

Cell lines and culture conditions. Human breast cancer cell lines MCF-7 and T47D were purchased from the American Type Culture Collection (ATCC, Manassas, VA, USA). Cells were kept in medium as previously described (16). The resistant sublines MCF-7-TR and T47D-TR were developed as described in detail (16), and the medium concentration of 4OH-tamoxifen (OHT; Sigma, Deisenhofen, Germany) was $1.25 \mu \mathrm{M}$. Re-evaluation of mRNA expression of $\mathrm{ER} \alpha / \mathrm{ER} \beta$, HER2, EGFR, and GnRH-I/II-R in the resistant sublines by PCR analysis and immunoprecipitation of ER, as well as apoptosis assays, showed no marked differences to results previously reported (16).

Flow cytometry analysis of surface expression of HER2, EGFR and IGFR. Flow cytometry was carried out as previously described (16). Antibodies: anti-HER2 (1:10; TAB250, Zymed Laboratories, San Francisco, CA, USA), monoclonal mouse anti-EGFR antibody (1:10; clone 29.1; Sigma), mouse anti-IGF-1R $\alpha$ (1:10; clone MOPC21, BD Biosciences, Frankfurt, Germany), FITC-conjugated secondary goat anti-mouse antibody (1:20; Sigma). Cells were analyzed by flow cytometry on FACSCalibur equipment using Cellquest software (Becton Dickinson, Mountain View, CA, USA).

Reverse transcription-PCR of gpr30, aibl, pten and 17. Total-RNA of all cell lines was isolated using RNeasy ${ }^{\mathrm{TM}}$ mini kit (Qiagen, Hilden, Germany), following manufacturer's instructions. Total-RNA ( $1 \mu \mathrm{g})$ was reverse transcribed using Superscript II (Promega, Mannheim, Germany), following company instructions and the cDNA amplified by PCR using Taq DNA polymerase (Roche, Mannheim, Germany). The PCR for gpr30 consisted of 35 cycles with an annealing temperature of $60^{\circ} \mathrm{C}$, whereas the PCR conditions for aibl and pten were 22 cycles and an annealing temperature of $57^{\circ} \mathrm{C}$ and 32 cycles with an annealing temperature of $51^{\circ} \mathrm{C}$, respectively. As an internal control, reverse transcription and amplification of the $l 7$ housekeeping gene mRNA was performed. Specific primers sequences for gpr30 (sense: 5'-CTCCAACAGCTGCCTA AACC-3', antisense: 5'-ATGTGGCCAAGGCTGTCTAC-3') for pten (sense: 5'-ACACCGCCAAATTTAATTGC-3', antisense: 5'-ACATAGCGCCTCTGACTGG-3'), for aibl (sense: 5'-TCAC TGAGATCCTCCATGAG-3', antisense: 5'-GGCATCTGTAAG CCTTGGTT-3') and for $l 7$ (sense: 5'-AGATGTACAGAACTGA AATTC-3', antisense:5'-ATTTACCAAGAGATCGAGCAA-3'), were designed using the program Primer 3 (Whitehead Institute for Biomedical Research. Cambridge, MA, USA). 
Preparation of cellular extract and immunoblotting. Equal amounts of protein were analyzed using SDS-PAGE. Extract from placental tissue served as control for analysis of cellular aromatase expression. After electrophoretic separation proteins were blotted onto nitrocellulose membranes (Hybond-ECL nitrocellulose membrane, GE Healthcare, Munich, Germany). After blocking and washing the western blots were incubated with the following antibodies: anti-Akt antibody (no. 9272), anti-phospho-Akt ( $\operatorname{Ser}^{473}$ ) antibody (no. 4058), anti-PTEN antibody (no. 9552), anti-phospho-p44/42 MAPK (Erk1/2) (Thr202/Tyr204) (no. 4376), anti-CTMP antibody (no. 4612) (all Cell Signaling Technology, Danvers, MA, USA), anti-Erk1 antibody (no. 14-6718, eBioscience, San Diego, CA, USA, recognizes also MAPK p42 Erk2), antiaromatase antibody (ab34193, Abcam, Cambridge, UK), GPR30 (LS-A1183, GeneTex, Irvine, CA, USA) or antiactin antibody (Sigma). Visualization of the protein bands was achieved by using an enhanced chemiluminescence (ECL) detection system (Millipore, Billerica, MA, USA) and a radiographic film (Kodak BioMax MR film, Kodak, Rochester, NY, USA).

DNA sequencing of pten and exons of pik3ca. Genomic DNA of cells was obtained using the innuPREP DNA mini kit (Analytik Jena, Jena, Germany). Primers for pten were specific for the 9 exons of the gene and were designed according to Bertelsen et al (26). Two exons of the pik3ca gene, which encodes for the catalytic subunit $\mathrm{p} 110 \alpha$ of the PI3K, were also sequenced. Primers for pik3ca were designed according to Curtin et al (27). All primers were purchased from biomers.net (Ulm, Germany) or MWG-Biotech (Ebersberg, Germany). A total of $1 \mu \mathrm{g}$ of each genomic DNA-sample was used in a PCR as described above to amplify the sequences of interest. After purification with the QIAquick 96 PCR Purification Kit (Qiagen), 125 ng DNA of every sample in $10 \mathrm{mM}$ Tris-Cl-Puffer ( $\mathrm{pH} 8.5)$ and $20 \mathrm{pmol}$ of every forward primer were brought to total volume of $7 \mu \mathrm{l}$ and sequenced. Sequencing was performed by Seqlab (Göttingen, Germany). If necessary, a second sample with the reverse primer was sequenced. Chromatograms of the sequenced samples were analysed with the software Chromas Lite 2.0 (Technelysium Pty Ltd, Tewantin, Queensland, Australia).

Array based comparative genomic hybridization (aCGH). aCGH was performed using a high density array system with 244,000 oligonucleotides on a chip (Cat. No. G4411B, Agilent, Waldbronn, Germany), covering the complete genome in an average of approximately 5-13 kb. DNA of the cell lines was isolated using the QIAamp DNA Mini kit, (Qiagen Cat. No. 51304), following the supplier's instructions for cultured cells. Labelling and hybridization was also done as described by the supplier. As a reference, DNA of a female donor was taken (Cat. No. G1521, Promega, Mannheim, Germany). Hybridization was performed for $40 \mathrm{~h}$ at $65^{\circ} \mathrm{C}$ in a hybridization oven (Agilent G2545A). After washing slides were scanned in a laser scanning system (Agilent microarray scanner G2565CA). Images were imported into the software package Genomic Workbench Standard Edition 5.0.14 (Agilent). Then raw data were processed using the feature extraction software component of this package and further analyzed in the DNA analytics part of the software. Image acquisition and analysis was performed as described in detail previously by Wilkens et al (28). At least 10 metaphase spreads were analyzed in each case.

Proliferation assays. Cells were placed on 96-well microplates in $100 \mu$ l MEM-Earl culture medium without phenol red supplemented with $10 \%$ (v/v) charcoal-stripped FCS (Allgaeu BioTech Service, Goerisried, Germany), 0.22\% (w/v) $\mathrm{NaHCO}_{3}$ and $2 \%$ (v/v) stable L-glutamine per well. After $24 \mathrm{~h} 100 \mu \mathrm{l}$ of medium with respective concentrations of drugs were added. This was repeated every $24 \mathrm{~h}$. After 48, 72 and 96 h $20 \mu \mathrm{l}$ of alamarBlue ${ }^{\mathrm{TM}}$ indicator dye (AbD Serotec, Duesseldorf, Germany) was added to each well and microplates were incubated for additional $4 \mathrm{~h}$ in the incubator at $37^{\circ} \mathrm{C}$. Absorbance at $570 \mathrm{nM}$ and as a reference at $600 \mathrm{nM}$ was measured in each well in a microplate reader (BioTek, Bad Friedrichshall, Germany). To analyze cross-resistance to OHT we tested the selective estrogen destabilisator fulvestrant (ICI 182780 AstraZeneca, Frankfurt, Germany). For inhibition of the erbB signal transduction we used MEK inhibitor PD98059 (Calbiochem Merck, Darmstadt, Germany) and EGFR tyrosine kinase inhibitor gefitinib (ZD1839/Iressa; AstraZeneca). To inhibit the PI3K/AKT/mTOR pathway we used rapamycin (Calbiochem Merck) and perifosine (Zentaris, Frankfurt, Germany). We performed dose- and time-dependent proliferation assays for each of the inhibitors. In the results we present the data of experiments with minimum concentrations of inhibitors yielding reproducible significant growth-inhibitory effects in parental MCF-7 and T47D cells after $96 \mathrm{~h}$ only, because we found no consistent growth-inhibitory effects after 48 and $72 \mathrm{~h}$.

Apoptosis assays. For apoptosis assays, cells were placed in 6 -well plates and kept under the same conditions as in the proliferation assays, using the same respective concentrations of drugs up to $96 \mathrm{~h}$. To quantify apoptosis we used a procedure based on detecting advanced DNA degradation as previously reported (16). Analysis was performed on a FACSCalibur (Becton Dickinson) equipment using Cellquest software. In each experiment $1 \times 10^{5}$ cells were counted. To verify the results obtained by this method an APO LOGIX ${ }^{\mathrm{TM}}$ - JC-1 Mitochondrial Membrane Potential Detection Kit (Bachem, Weil am Rhein, Germany) was used. Cells were cultured and treated as described above and then the mitochondrial membrane potential assay carried out following the manufacturer's instructions. The results of the APO LOGIX-JC-1 test of early apoptosis events yielded comparable percentages of apoptotic cells to those with delayed advanced DNA degradation detected by the method described above. We present the results of cells with advanced DNA degradation.

Immunoprecipitaion of inhibited AKT activation. Resistant cell lines MCF-7TR and T47D-TR were grown to $70 \%$ confluence and then cultured according to the proliferation- and apoptosisassays before starting treatment with GnRH-I agonist triptorelin (100 nM; Ferring Pharmaceuticals, Copenhagen, Denmark), GnRH-II agonist [D-Lys ${ }^{6}$ GnRH-II (100 nM; developed in our lab and synthesized by Peptide Specialty Laboratories $\mathrm{GmbH}$, Heidelberg, Germany), gefitinib (4.5 $\mu \mathrm{M})$ and perifosine $(30 \mu \mathrm{M})$. Treatment with gefitinib, triptorelin and [D-Lys ${ }^{6}$ ] GnRH-II was carried out for 15, 30, 45 and $60 \mathrm{~min}$, and with 
Table I. Comparative genomic hybridization of MCF-7-TR and T47D-TR cells compared to parental cell lines MCF-7 and T47D.

\begin{tabular}{cllr}
\hline & \multicolumn{1}{c}{ Gene gains } & \multicolumn{1}{c}{ Gene losses } & No or minor changes \\
\hline MCF-7-TR & $1 \mathrm{p}, 3 \mathrm{q}, 5 \mathrm{q}, 6 \mathrm{p}, 7 \mathrm{q}, 8 \mathrm{q}$, & $1 \mathrm{q}, 2 \mathrm{q}, 4 \mathrm{p}, 5 \mathrm{p}, 6 \mathrm{q}, 7 \mathrm{p}, 8 \mathrm{p}, 9 \mathrm{p}$, & $10,1219, \mathrm{X}$ \\
T47D-TR & $14 \mathrm{q}, 16 \mathrm{q}, 17 \mathrm{q}, 20 \mathrm{q}$ & $11 \mathrm{p}, 13 \mathrm{q}, 15 \mathrm{q}, 18 \mathrm{q}, 20 \mathrm{p}, 21 \mathrm{q}, 22 \mathrm{q}$ & \\
& $13 \mathrm{q}$ & $5 \mathrm{q}, 6 \mathrm{q}, 14 \mathrm{q}, 17 \mathrm{q}, 21 \mathrm{q}, \mathrm{Xp}, \mathrm{Xq}$ & $1,2,3,4,7,8,9,10,11$, \\
& & & $12,15,16,18,19,20,22$
\end{tabular}

perifosine up to $72 \mathrm{~h}$. After the treatment cells were lysed and the extracts were prepared for immunoblotting as described above.

Expression of receptors for GnRH-I and GnRH-II in breast cancers. Paraffin-embedded tumor samples of 100 patients with early breast cancer treated at our institution in 2006 were analyzed for expression of receptors for GnRH-I and GnRH-II by immunohistochemistry (29). No patients had distant metastases; 38 patients presented at stage I, 47 at stage II and 15 at stage III. Eighty-four patients had invasive ductal cancer, 16 invasive lobular cancer. Positive expression of receptors for GnRH-I/II, ER and progesterone receptor (PR) was defined by an Allred score of at least 3. Expression was compared to overexpression of HER2, defined by HercepTest score 3+ or $2+$ and amplification in FISH and ER expression. All patients gave informed consent for experimental analysis on their specimens.

Statistical analysis. A minimum of three repetitions was performed on PCR, immunoblotting, proliferation assays and apotosis assays. Data obtained from the proliferation and apoptosis assays were tested for significant differences by one-way ANOVA followed by Student-Newman-Keuls' test for comparison of individual groups. Mean values of receptor expression in breast cancer samples were compared by two-tailed t-tests and a correlation matrix was composed using Pearson's $r$ correlation coefficients. Statistical analyses were performed using GraphPad Prism Software 5.0.

\section{Results}

Comparative expression analysis and sequencing of pten and pik3 $\mathrm{ca}$. Analysis of surface expression showed similar levels of EGFR in T47D and the resistant T47D-TR cells, but reduced EGFR expression in MCF-7-TR cells compared to parental cells. Both resistant cell lines showed increased expression of HER2, which was more pronounced in T47D-TR cells. Both resistant cell lines showed clearly reduced expression of IGFR (Fig. 1). Comparing cellular aromatase expression to human placental tissue we could not detect aromatase expression in any cell line (data not shown). Expression of GPR30 was slightly decreased in both resistant cell lines as shown by PCR and immunoblotting (Fig. 2, PCR not shown). There was no significant difference in expression of aibl measured by PCR (data not shown). There was no difference in expression of PTEN (Fig. 2, PCR not shown). Compared to parental cells no difference in basal expression of MAPK
(ERK-1/2) was found in the resistant sublines, while activated MAPK was increased in T47D-TR cells but not in MCF-7-TR cells (Fig. 2). Basal AKT expression was more similar in the sublines compared to parental cells, but AKT activation was found in both resistant sublines (Fig. 2). MCF-7-TR cells showed complete loss of CTMP expression, while CTMP expression in T47D-TR was comparable to parental cells (Fig. 2). Sequencing of pten and exons of pik3ca confirmed previously reported mutations in T47D cells, which were also found in T47D-TR cells, but not in MCF-7 and MCF-7-TR cells.

Comparative genomic hybridization (CGH). CGH analyses revealed appreciable aberrations in resistant sublines compared to parental cells, which were predominantly gene losses. Aberrations listed in Table I refer to gains and losses of each chromosome of each resistant subline compared to parental cells. The only consistent aberrations for both resistant sublines were major copy number losses on chromosomes $6 q$ and $21 q$. Detailed comparative analysis of gene losses or amplifications of parental and resistant cell lines yielded only a few genes previously reported to be associated to erbB, PI3K/AKT and ER mediated growth regulation. In particular, T47D-TR cells showed amplification of the sprouty homolog 2 gene (SPRY2) on chromosome 13 (location 13q31.1), and MCF-7-TR showed amplification of the breast carcinoma amplified sequence-3 (BCAS3) gene on chromosome 17 (location 17q23). We found no difference in the PAX2 or CTMP gene between the resistant cell lines.

Inhibition of proliferation and induction of apoptosis. OHT $(2.5 \mu \mathrm{M})$ and fulvestrant $(100 \mathrm{nM})$ inhibited proliferation and induced apoptosis in MCF-7 and T47D cells, but had no significant effect on proliferation and apoptosis in the resistant sublines; apoptosis in MCF-7 cells: control 8.1 $\pm 3.4 \%$, OHT $18.3 \pm 2.5 \%$ ( $\mathrm{p}<0.01$ vs. control), fulvestrant $18.7 \pm 8 \%(\mathrm{p}<0.05$ vs. control); apoptosis in T47D cells: control 10.2 $\pm 4 \%$, OHT $19.4 \pm 2.8 \%$, fulvestrant $18.9 \pm 3.3 \%$ (both $\mathrm{p}<0.01$ vs. control)] (Figs. 3 and 4). Specific inhibitors of the EGFR/MAPK and the AKT/mTOR pathways were evaluated for significant antiproliferative effects in MCF-7 and T47D cells. After $96 \mathrm{~h}$ of treatment the inhibitor of the EGFR associated tyrosine kinase gefitinib $(4.5 \mu \mathrm{M})$, the MEK inhibitor PD98059 (5 $\mu \mathrm{M})$, rapamycin $(20 \mathrm{nM})$ and the AKT inhibitor perifosine $(30 \mu \mathrm{M})$ showed reproducible antiproliferative effects. In contrast to T47D-TR cells, PD98059 had no significant antiproliferative effect on MCF-TR cells, but gefitinib, rapamycin and perifosine showed growth-inhibitory effects comparable to those of parental 


\section{EGF-Receptor}
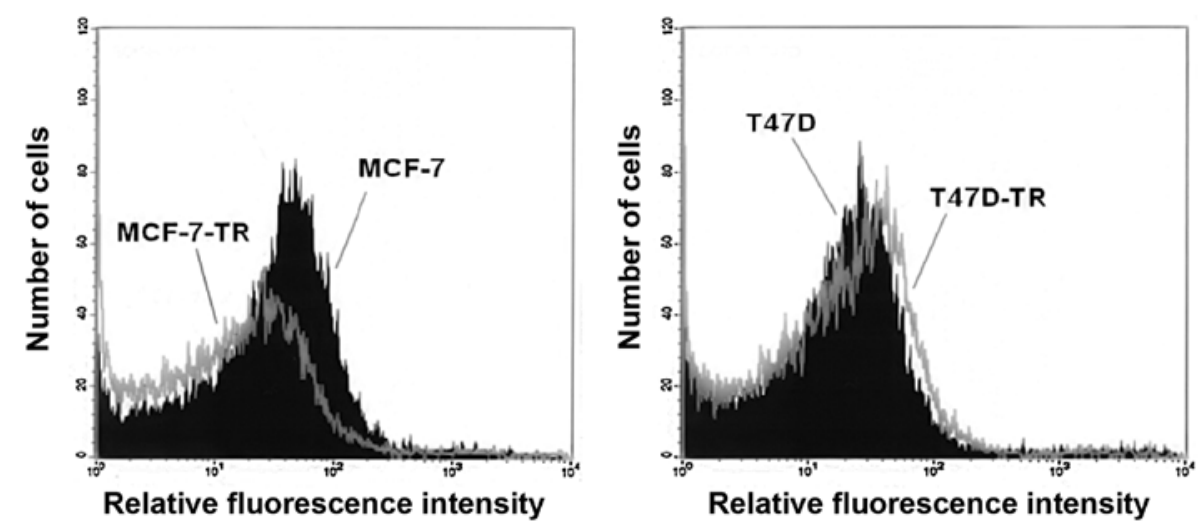

HER-2

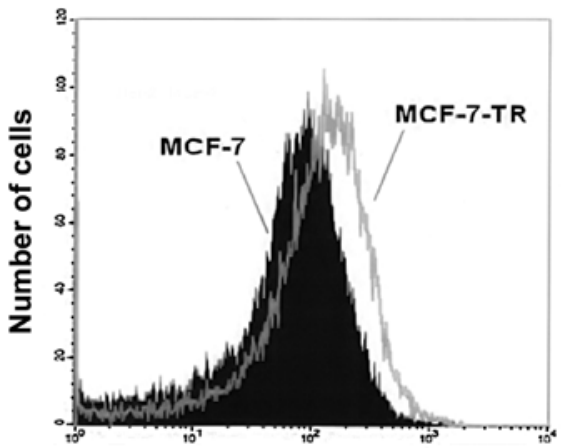

Relative fluorescence intensity

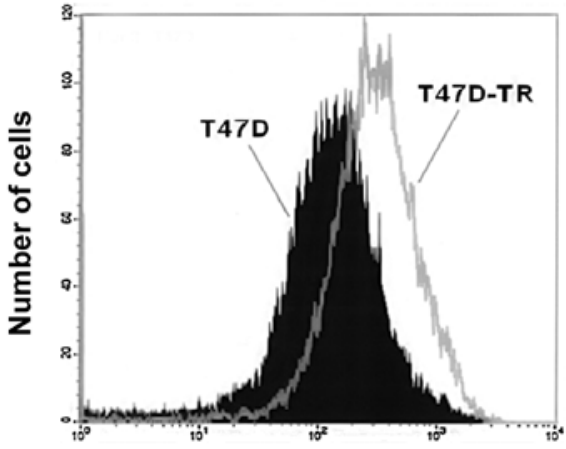

Relative fluorescence intensity

IGF-Receptor
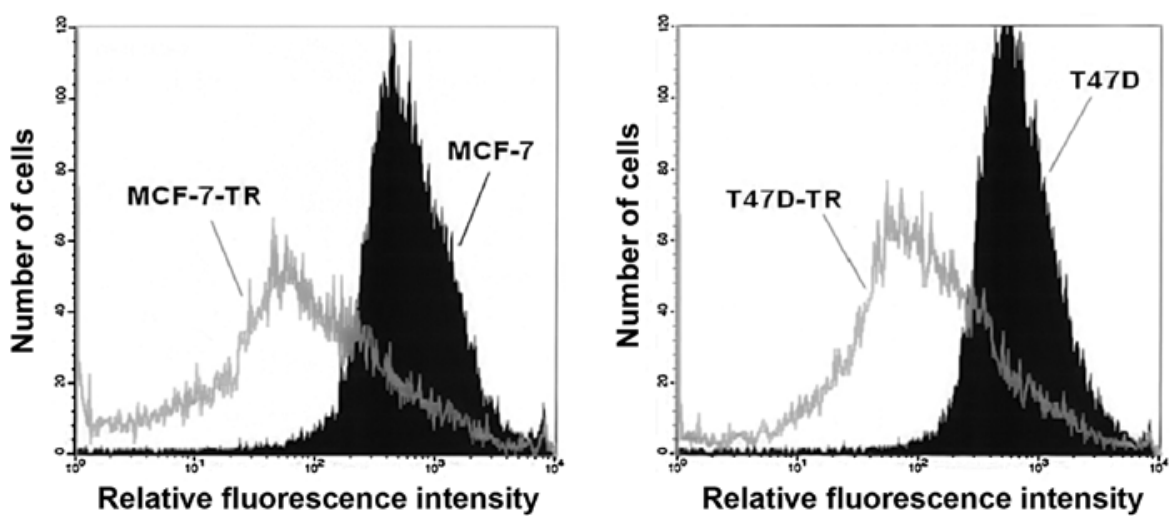

Figure 1. Comparable flow cytometry analysis of cell surface expression of EGFR, HER2 and IGFR. OHT-resistant MCF-7-TR cells showed clearly decreased EGFR expression, while in T47D-TR we found no difference of EGFR expression compared to parental cells. Both resistant sublines showed increased HER2 expression, but this was more pronounced in T47D-TR cells. IGFR expression was remarkably decreased in both resistant sublines.

cells in both resistant sublines (Fig. 3). Addition of OHT to any specific inhibitor had no significant effect on proliferation in the resistant sublines compared to single-agent treatment (Fig. 3). After $96 \mathrm{~h}$ perifosine (30 $\mu \mathrm{M})$ and rapamycin $(20 \mathrm{nM})$ induced apoptosis in MCF-7 cells [spontaneous apoptosis rate in control cells $8.1 \pm 3.4 \%$, perifosine $19.5 \pm 2.4 \%$ ( $p<0.001$ vs. control), rapamycin $15.7 \pm 5.7 \%$ ( $<<0.01$ vs. control)], but not in T47D cells. In the resistant sublines no single-agent treatment significantly induced apoptosis after 96 h. In MCF-7-TR cells the combination of perifosine and OHT significantly increased apoptosis [spontaneous apoptosis rate in control cells $10.5 \pm 3.2 \%$, perifosine plus OHT $27 \pm 9.2 \%$ ( $p<0.001$ vs. control, OHT and perifosine)] (Fig. 4). In T47D-TR cells the combination of gefitinib and OHT showed significant apoptotic effects [spontaneous apoptosis rate in control cells $9.4 \pm 5.9 \%$, gefitinib plus OHT $24.7 \pm 6.2 \%$ ( $<<0.001$ vs. control and OHT, $p<0.01$ vs. gefitinib)]. All other combinations with OHT showed no significant apoptotic effects. 
MCF-7 MCF-7-TR T47D T47D-TR

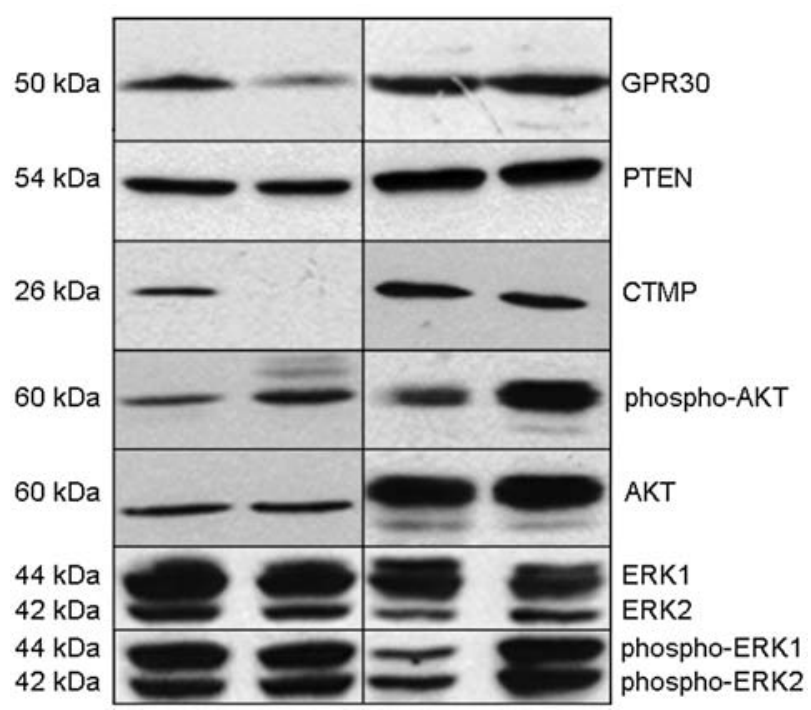

Figure 2. Representative results of immunoblotting of GPR30, PTEN, CTMP, basal and activated AKT, and basal and activated MAPK (ERK-1/2). Expression of GPR30 was decreased in both OHT-resistant sublines. In comparison to parental cells there was no difference in expression of PTEN, basal MAPK (ERK-1/2) and basal AKT in the resistant sublines. MCF-7-TR cells showed total loss of CTMP expression, while altered CTMP expression was not found in T47D-TR cells. Increased AKT activation was found in both resistant sublines. Increased MAPK activation was only found in T47D-TR cells.
Effects of perifosine, gefitinib, triptorelin and [D-Lys $\left.{ }^{6}\right] G n R H-I I$ on AKT expression and activation. In the resistant sublines MCF-7-TR and T47D-TR perifosine activated AKT during the first hour of treatment, but after $72 \mathrm{~h}$ the amount of activated AKT was lower compared to untreated control cells. In MCF-7-TR cells perifosine had no effect on basal AKT expression, but in T47D-TR cells basal AKT was clearly decreased after $45 \mathrm{~min}$, and levels remained low until $72 \mathrm{~h}$. Gefitinib did not affect basal expression of AKT in MCF-7-TR and T47D-TR cells during the first hour of treatment. Gefitinib inhibited AKT activation in T47D-TR cells, but not in MCF-7-TR cells. In both resistant sublines activation of AKT was inhibited during the $1 \mathrm{~h}$ of treatment with triptorelin or [D-Lys $\left.{ }^{6}\right] \mathrm{GnRH}-\mathrm{II}$ (Fig. 5).

Expression of receptors for GnRH-I and GnRH-II in human breast cancers. Specimens of 100 breast cancers showed positive expression (Allred score $>2$ ) for GnRH-I receptor in $46 \%$, and for GnRH-II receptor in 53\%. ER expression (Allred score $>2$ ) was found in $63 \%$ of tumors, and HER2 overexpression (HercepTest $3+$ or 2+ and amplified in FISH) was found in $38 \%$. GnRH-I receptor expression was positively correlated with GnRH-II receptor expression $(r=0.34 ; p=0.0004)$ and HER2 overexpression ( $\mathrm{r}=0.23 ; \mathrm{p}=0.02)$, but not with ER expression. GnRH-II receptor expression was also positively correlated with HER 2 overexpression ( $r=0.2 ; p=0.05)$, but not with ER
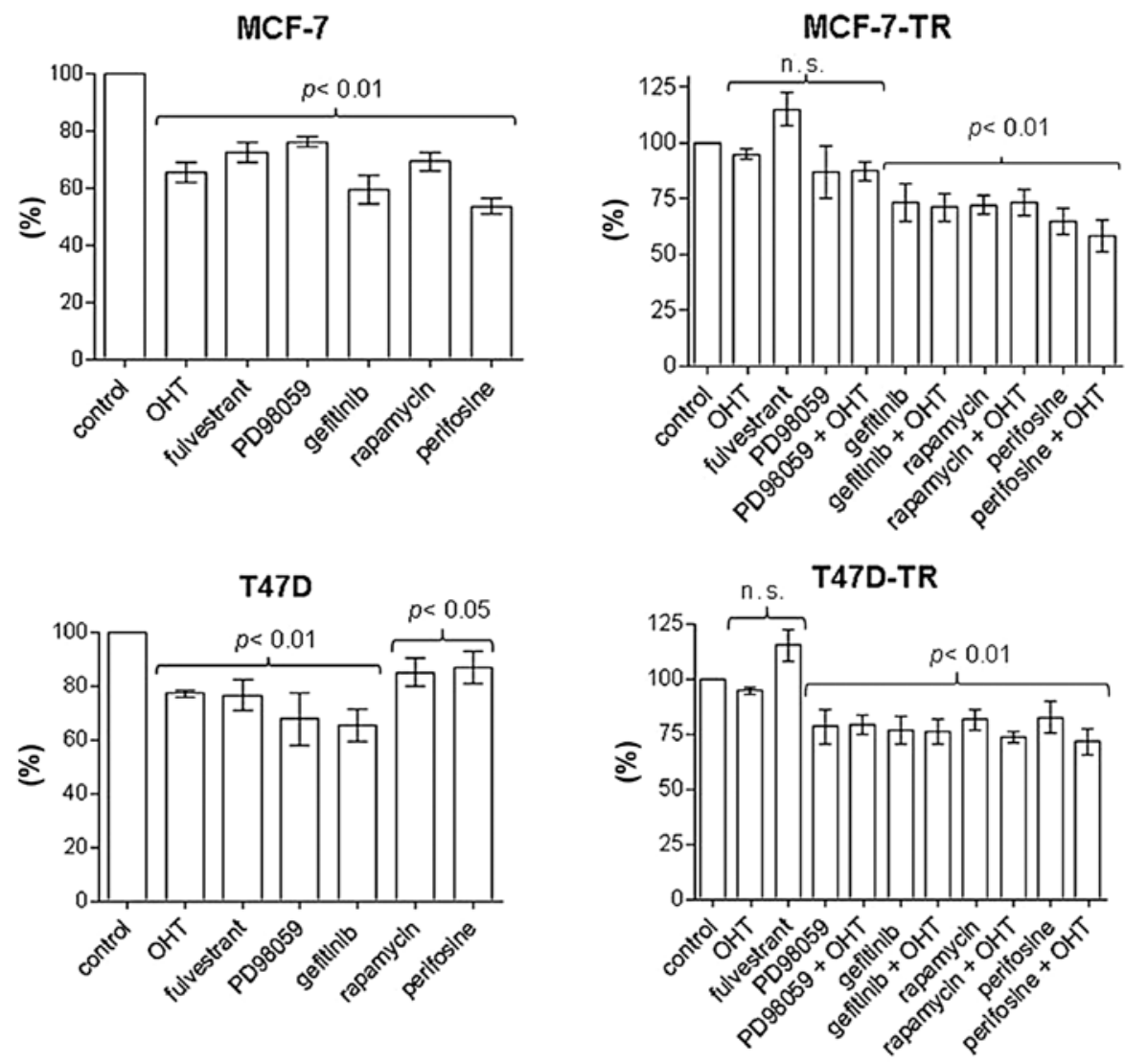

Figure 3. Proliferation assays in MCF-7 and T47D cells and the respective sublines after $96 \mathrm{~h}$ of treatment. Established antiproliferative concentrations of each inhibitor were evaluated in the respective sublines as single-agent treatment and in combination with OHT. In MCF-7-TR cells we found no significant antiproliferative effects with OHT, fulvestrant and PD98058 ( \pm OHT). All other drugs showed antiproliferative effects comparable to treatment in parental MCF-7 cells. In T47D-TR cells we found no significant antiproliferative effects of OHT and fulvestrant, all other agents showed antiproliferative effects comparable to parental cells. Addition of OHT to any inhibitor showed no significant effects compared to single-agent treatment in both resistant sublines. Columns show percentages of counted cells and represent means and SEM of four independent experiments. Shown significance levels are vs. control. 
MCF-7

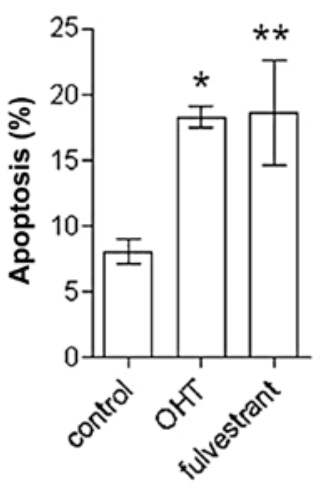

T47D

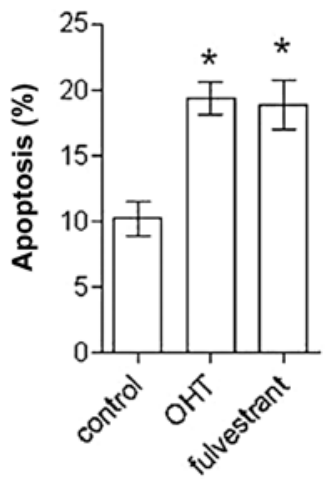

MCF-7-TR

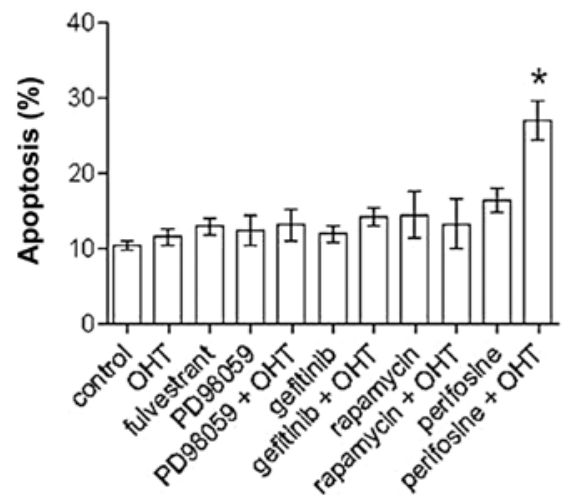

T47D-TR

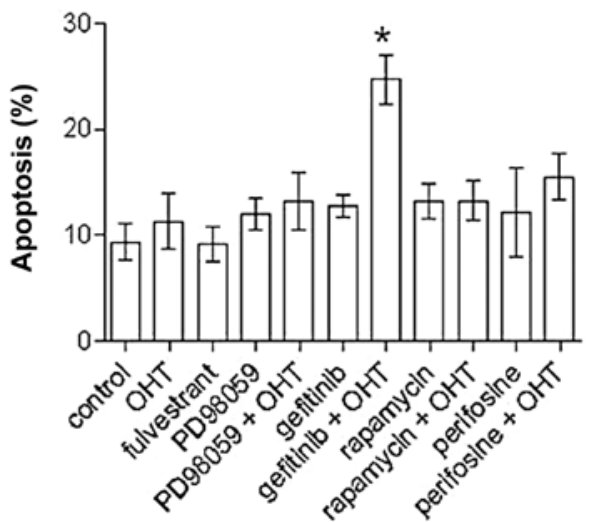

Figure 4. Apoptosis assays in MCF-7 and T47D cells and the respective sublines after $96 \mathrm{~h}$ of treatment. Effective concentrations of proliferations assays of each inhibitor were evaluated in the respective sublines as single-agent treatment and in combination with OHT. Apoptosis was quantified based on advanced DNA degradation by flow cytometry. Both OHT-resistant sublines showed cross-resistance to fulvestrant. In MCF-7-TR cells only perifosine plus OHT significantly induced apoptosis. In T47D-TR cells only gefitinib plus OHT significantly induced apoptosis. Columns show percentages of apoptotic cells and represent means and SEM of four independent experiments. MCF-7: " $\mathrm{p}<0.01 \mathrm{vs.} \mathrm{control,}{ }^{* *} \mathrm{p}<0.05$ vs. control; MCF-7-TR: " $\mathrm{p}<0.001 \mathrm{vs.} \mathrm{control,} \mathrm{OHT} \mathrm{and} \mathrm{perifosine;} \mathrm{T47D:}{ }^{*}$ p<0.01 vs. control; T47D-TR: *p<.001 vs. control and OHT, p<0.01 vs. gefitinib.

expression. In this sample, ER expression showed no significant correlation to HER2 overexpression. There was no ER-positive/ PR-negative tumor. Nineteen tumors were negative for ER/PR and HER-2, and in these specimens GnRH-I and/or GnRH-II receptor expression was found in 10 cases, of which 7 cases showed expression of both receptors.

\section{Discussion}

In our model of OHT-resistant breast cancer cells, antiestrogen resistance was due to numerous genomic aberrations, which caused minor but important phenotype differences of both compared cell lines. Both resistant sublines shared similarities, such as increased HER2 expression, activated AKT, decreased IGFR and GPR30 expression, but also important differences were found, such as decreased EGFR expression and loss of CTMP expression in MCF-7-TR cells, and erbBassociated activated MAPK (ERK-1/2) in T47D-TR cells. The AKT-inhibitor perifosine was successful in overcoming tamoxifen resistance in MCF-7-TR cells with loss of CTMP expression, but not in T47D-TR cells. ErbB-inhibition by gefitinib to overcome tamoxifen resistance was only successful in T47D-TR cells. We found major genomic aberrations in both cell lines, mainly gene losses, confirming not only altered expression profiles but indeed the development of mutated subclones of parental cells. These subclones showed crossresistance to fulvestrant, reduced GPR30 expression and no detectable aromatase exn our model of OHT-resistant breast cancer cells, antiestrogen resistance was due to numerous genomic aberrations, which caused minor but important phenotype differences of the compared cell lines. Both resistant sublines shared similarities, pression, therefore autocrine estrogen-mediated growth control is unlikely.

In contrast to many previous reports on antiestrogen-resistant breast cancer models, resistance was not due to increased expression of AIB1, EGFR, IGFR and loss or mutation of PTEN and PIK3CA. However, we found BCAS3 amplification in MCF-7-TR, which was reported to act as ER $\alpha$ co-activator and to communicate with metastasis-associated protein-1 (MTA1) in tumor progression and tamoxifen resistance of breast cancer, and also to affect non-genomic ER $\alpha$ activation through MAPK and PI3K/AKT signalling pathways in combination with PELP1/MNAR (30-32). Expression of wildtype tumor suppressor gene product $h S P R Y 2$ is frequently downregulated in breast cancer overexpressing HER2, despite the fact that $h S P R Y 2$ does not act as general inhibitor of erbB associated tyrosine kinases and ERK-1/2 (33). However, we found SPRY2 gene amplification of T47D-TR cells, which 

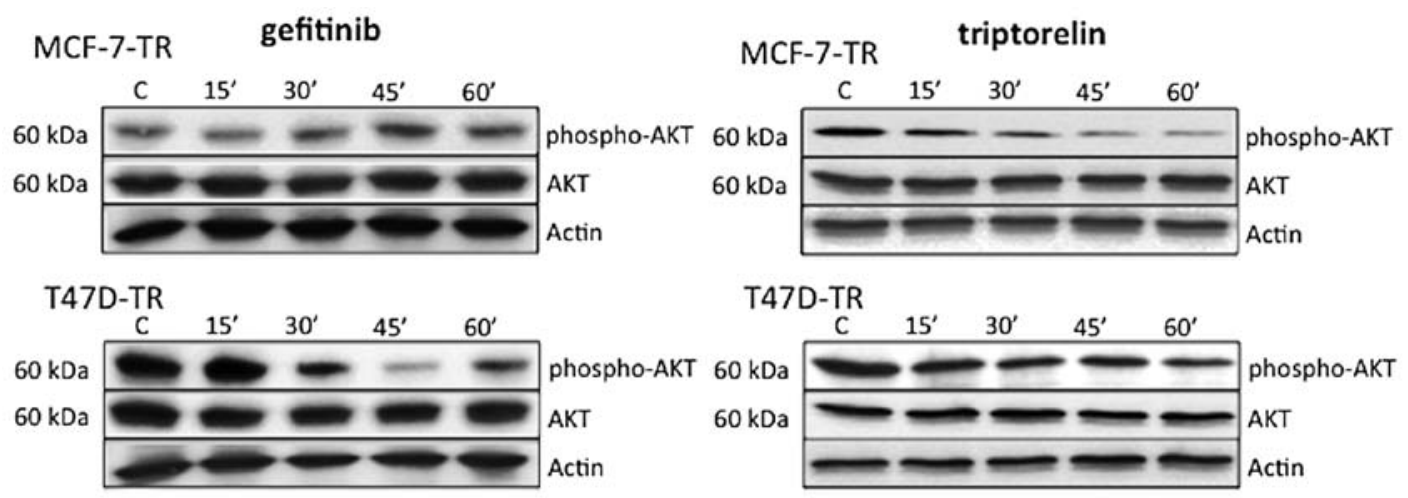

MCF-7-TR perifosine

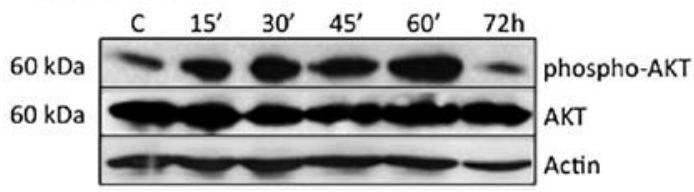

T47D-TR

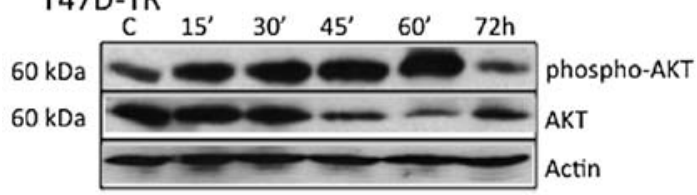

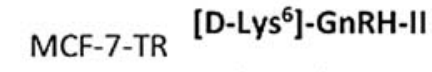
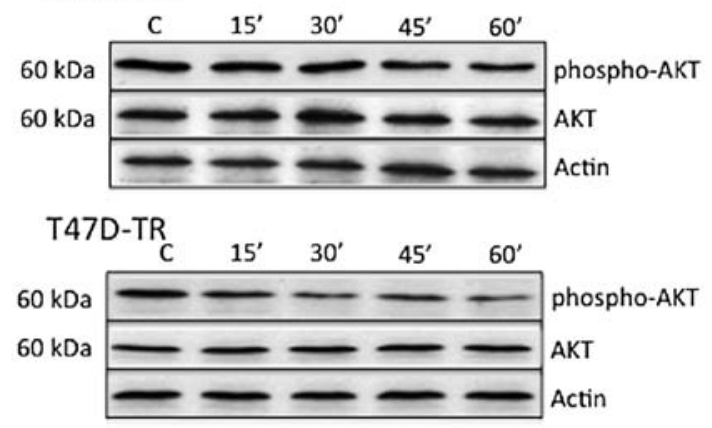

Figure 5. Representative results of immunoblotting of inhibitory effects on AKT and pAKT of gefitinib, triptorelin and [D-Lys $\left.{ }^{6}\right] \mathrm{GnRH}-\mathrm{II}$ during the first hour of treatment and of perifosine during the first hour and after $72 \mathrm{~h}$. Gefitinib inhibited AKT activation only in T47D-TR cells. The AKT-inhibitor perifosine showed its inhibitory effects after a delay of $72 \mathrm{~h}$ in both resistant sublines. Triptorelin and [D-Lys $\left.{ }^{6}\right] \mathrm{GnRH}-\mathrm{II}$ inhibited AKT activation in both resistant sublines.

may reflect a protective effect as regulator of the Ras/MAPK pathway against hormonal changes e.g. ER-inhibition by OHT. Nevertheless, the SPRY2 gene in breast cancer development and drug resistance still needs to be investigated (33). Previous, very well described in vitro and in vivo models of breast cancer cells with acquired antiestrogen-resistance explained development of resistance by different mechanisms $(8,12,13,15,21,34-36)$. In cell models with proven agonistic activity of tamoxifen, resistance was frequently associated with increased HER2 expression, activation of MAPK (ERK-1/2), downregulation of PAX2, increased expression of AIB1 and/or activation of IGFR/AKT signalling, and inhibitors of erbB signalling delayed tamoxifen resistance or restored its antiproliferative action $(1,8,13,15,21,34,36,37)$. In cells with long-term estrogen-deprivation or long-term exposure to fulvestrant IGFR downregulation and activation of HER2/erbB3/MAPK was reported. In these cells resistance could be delayed by anti-HER2/EGFR treatment, but reactivation of HER2 and signalling through AKT lead to anti-ER/anti-erbB de novo resistance $(15,35,36)$. Especially in ER-positive cells multi-targeting of erbB mediators might be an option to prevent resistance, even at initially low expression of HER $2(12,14,35,36,38)$. Besides, anti-erbB treatment with trastuzumab, pertuzumab, lapatinib and gefitinib, targeting MAPK and PI3K/AKT/mTOR signal transduction is also an option to prevent or overcome antiestrogen resistance $(21,22)$. The MEK inhibitor PD98059, which was demonstrated to be active in tamoxifen-resistant cells (21), failed to restore the effects of OHT in both of our resistant sublines. Inhibition of
mTOR by rapamycin also failed to restore OHT sensitivity in our model. Thus, AKT activation alone is not a predictor of response to rapamycin. The AKT inhibitor perifosine acts by decreasing plasma membrane localization of AKT, inhibition of AKT phosphorylation, and reduction of the levels of total AKT (39). Both resistant sublines showed increased AKT activity, but perifosine restored OHT sensitivity only in MCF-7-TR cells with loss of CTMP expression. However, we have no explanation for the flair-up effect of perifosine on AKT activation in the resistant sublines during the first hour of treatment, which was not found in parental cells (data not shown). In MCF-7-TR cells gefitinib and PD98059 had no effect in combination with OHT, which suggests an erbBindependent growth regulation. In tamoxifen-resistant breast cancer cells with downregulated IGFR signal transduction it has been shown that the inhibitory effects on mediators of erbB and AKT were abrogated (40). In comparison, in T47D-TR cells the increase of HER2 expression was more pronounced, EGFR expression was not decreased, and inhibition of EGFR by gefitinib restored OHT sensitivity, which suggests a primarily erbB-mediated cause of antiestrogen resistance.

Regarding analogs of GnRH-I/II to overcome tamoxifen resistance, we previously showed that analogs of GnRH-I and GnRH-II inhibited MAPK activity and restored OHT sensitivity in our resistant sublines (16), herein we also demonstrate the inhibition of AKT activation in these cells. GnRH-I receptor expression was described in about 50-64\% of breast cancers $(41,42)$. Antiproliferative effects of analogs of GnRH-I 
alone or in combination with tamoxifen in breast cancer cells were already reported 25 years ago $(43,44)$. In gynecologic malignancies, analogs of GnRH-I activate a G-protein coupled phosphotyrosine phosphatase and antagonize EGFR-mediated mitogenic signal transduction $(16,18,19,45)$. We detected a GnRH-II receptor-like antigen in human placenta and gynecologic cancers including breast cancer cells, and showed that the antiproliferative effects of GnRH-II and the GnRH-I antagonist cetrorelix in tumor cells were not mediated through the GnRH-I receptor $(16,29,46,47)$. Analogs of GnRH-I and GnRH-II inhibited activation of MAPK (ERK-1/2) and AKT, and restored OHT sensitivity in both resistant cell lines of our model. Here we confirm the expression of GnRH-I receptor in approximately $50 \%$ of breast cancers and are the first to report on GnRH-II receptor expression in more than $50 \%$ of breast cancers, with both receptors correlating to HER2, but not to ER expression. Buchholz et al found expression of GnRH-I receptor in particular in triple-negative breast cancers (48). More recently, GnRH-II antagonists induced apoptosis in human gynecologic malignancies and breast cancers in vivo and in vitro, without any apparent side effects in nude mice $(49,50)$. In endocrine-resistant, HER2 overexpressing or triple-negative breast cancer, GnRH-I/II receptor expression provides potential targets in multi-targeting therapy strategies to avoid or overcome drug resistance.

\section{Acknowledgements}

We thank Renate Dietrich, Matthias Läsche, Hiltrud Schulz and Sonja Blume for excellent technical assistance. We also thank Prisca Eser, Brett McKinnon and Stefan Aebi for proofreading the manuscript. This study was supported by the Deutsche Forschungsgemeinschaft (DFG GU 981/1-1 to Andreas Günthert).

\section{References}

1. Prat A and Perou CM: Mammary development meets cancer genomics. Nat Med 15: 842-844, 2009.

2. Cheang MC, Chia SK, Voduc D, Gao D, Leung S, Snider J, Watson M, Davies S, Bernard PS, Parker JS, Perou CM, Ellis MJ and Nielsen TO: Ki67 index, HER2 status, and prognosis of patients with luminal B breast cancer. J Natl Cancer Inst 101: 736-750, 2009.

3. Early Breast Cancer Trialists' Collaborative Group (EBCTCG): Effects of chemotherapy and hormonal therapy for early breast cancer on recurrence and 15-year survival: an overview of the randomised trials. Lancet 365: 1687-1717, 2005.

4. Aitken SJ, Thomas JS, Langdon SP, Harrison DJ and Faratian D: Quantitative analysis of changes in ER, PR and HER2 expression in primary breast cancer and paired nodal metastases. Ann Oncol 21: 1254-1261, 2009.

5. Osborne CK, Bardou V, Hopp TA, Chamness GC Hilsenbeck SG, Fuqua SA, Wong J, Allred DC, Clark GM and Schiff R: Role of the estrogen receptor coactivator AIB1 (SRC-3) and HER-2/neu in tamoxifen resistance in breast cancer. J Natl Cancer Inst 95: 353-361, 2003.

6. Dowsett M, Houghton J, Iden C, Salter J, Farndon J, A'Hern R, Sainsbury $R$ and Baum M: Benefit from adjuvant tamoxifen therapy in primary breast cancer patients according oestrogen receptor, progesterone receptor, EGF receptor and HER2 status. Ann Oncol 17: 818-826, 2006.

7. Dihge L, Bendahl PO, Grabau D, Isola J, Lövgren K, Rydén L and Fernö M: Epidermal growth factor receptor (EGFR) and the estrogen receptor modulator amplified in breast cancer (AIB1) for predicting clinical outcome after adjuvant tamoxifen in breast cancer. Breast Cancer Res Treat 109: 255-262, 2008.
8. Hurtado A, Holmes KA, Geistlinger TR, Hutcheson IR, Nicholson RI, Brown M, Jiang J, Howat WJ, Ali S and Carroll JS: Regulation of ERBB2 by oestrogen receptor-PAX2 determines response to tamoxifen. Nature 456: 663-666, 2008.

9. Ball LJ, Levy N, Zhao X, Griffin C, Tagliaferri M, Cohen I, Ricke WA, Speed TP, Firestone GL and Leitman DC: Cell typeand estrogen receptor-subtype specific regulation of selective estrogen receptor modulator regulatory elements. Mol Cell Endocrinol 299: 204-211, 2009.

10. Kirkegaard T, McGlynn LM, Campbell FM, Müller S, Tovey SM, Dunne B, Nielsen KV, Cooke TG and Bartlett JM: Amplified in breast cancer 1 in human epidermal growth factor receptor - positive tumors of tamoxifen-treated breast cancer patients. Clin Cancer Res 13: 1405-1411, 2007.

11. Pérez-Tenorio G and Stål O: Activation of AKT/PKB in breast cancer predicts a worse outcome among endocrine treated patients. Br J Cancer 86: 540-545, 2002.

12. Leary AF, Drury S, Detre S, Pancholi S, Lykkesfeldt AE, Martin LA, Dowsett M and Johnston SR: Lapatinib restores hormone sensitivity with differential effects on estrogen receptor signaling in cell models of human epidermal growth factor receptor 2-negative breast cancer with acquired endocrine resistance. Clin Cancer Res 16: 1486-1497, 2010.

13. Shou J, Massarweh S, Osborne CK, Wakeling AE, Ali S, Weiss $\mathrm{H}$ and Schiff R: Mechanisms of tamoxifen resistance: increased estrogen receptor-HER 2/neu cross-talk in ER/HER2positive breast cancer. J Natl Cancer Inst 96: 926-935, 2004.

14. Konecny GE, Pegram MD, Venkatesan N, Finn R, Yang G, Rahmeh M, Untch M, Rusnak DW, Spehar G, Mullin RJ, Keith BR, Gilmer TM, Berger M, Podratz KC and Slamon DJ: Activity of the dual kinase inhibitor lapatinib (GW572016) against HER-2-overexpressing and trastuzumab-treated breast cancer cells. Cancer Res 66: 1630-1639, 2006.

15. Frogne T, Benjaminsen RV, Sonne-Hansen K, Sorensen BS, Nexo E, Laenkholm AV, Rasmussen LM, Riese DJ II, de Cremoux P, Stenvang J and Lykkesfeldt AE: Activation of ErbB3, EGFR and Erk is essential for growth of human breast cancer cell lines with acquired resistance to fulvestrant. Breast Cancer Res Treat 114: 263-275, 2009.

16. Günthert AR, Gründker C, Olota A, Läsche J, Eicke N and Emons G: Analogs of GnRH-I and GnRH-II inhibit epidermal growth factor-induced signal transduction and resensitize resistant human breast cancer cells to $4 \mathrm{OH}$-tamoxifen. Eur J Endocrinol 153: 613-625, 2005.

17. Emons G, Müller V, Ortmann O and Schulz KD: Effects of LHRH-analogues on mitogenic signal transduction in cancer cells. J Steroid Biochem Mol Biol 65: 199-206, 1998.

18. Gründker C, Völker P, Schulz KD and Emons G: Luteinizing hormone-releasing hormone agonist triptorelin and antagonist cetrorelix inhibit EGF-induced c-fos expression in human gynecological cancers. Gynecol Oncol 78: 194-202, 2000.

19. Gründker C, Völker P and Emons G: Antiproliferative signaling of luteinizing hormone-releasing hormone in human endometrial and ovarian cancer cells through $G$ protein alpha(I)-mediated activation of phosphotyrosine phosphatase. Endocrinology 142: 2369-2380, 2001.

20. Kraus S, Levy G, Hanoch T, Naor Z and Seger R: Gonadotropinreleasing hormone induces apoptosis of prostate cancer cells: role of c-Jun NH2-terminal kinase, protein kinase $\mathrm{B}$, and extracellular signal-regulated kinase pathways. Cancer Res 64: 5736-5744, 2004.

21. Ghayad SE, Vendrell JA, Larbi SB, Dumontet C, Bieche I and Cohen PA: Endocrine resistance associated with activated ErbB system in breast cancer cells is reversed by inhibiting MAPK or PI3K/Akt signaling pathways. Int J Cancer 126: 545-562, 2010.

22. deGraffenried LA, Friedrichs WE, Russell DH, Donzis EJ, Middleton AK, Silva JM, Roth RA and Hidalgo M: Inhibition of mTOR activity restores tamoxifen response in breast cancer cells with aberrant Akt Activity. Clin Cancer Res 10: 8059-8067, 2004.

23. Chow LM and Baker SJ: PTEN function in normal and neoplastic growth. Cancer Lett 241: 184-196, 2006.

24. Maira SM, Galetic I, Brazil DP, Kaech S, Ingley E, Thelen M and Hemmings BA: Carboxyl-terminal modulator protein (CTMP), a negative regulator of PKB/Akt and v-Akt at the plasma membrane. Science 294: 374-380, 2001.

25. Revankar CM, Mitchell HD, Field AS, Burai R, Corona C, Ramesh C, Sklar LA, Arterburn JB and Prossnitz ER: Synthetic estrogen derivatives demonstrate the functionality of intracellular GPR30. ACS Chem Biol 2: 536-544, 2007. 
26. Bertelsen BI, Steine SJ, Sandvei R, Molven A and Laerum OD Molecular analysis of the PI3K-AKT pathway in uterine cervical neoplasia: frequent PIK3CA amplification and AKT phosphorylation. Int J Cancer 118: 1877-1883, 2006.

27. Curtin JA, Stark MS, Pinkel D, Hayward NK and Bastian BC: PI3-kinase subunits are infrequent somatic targets in melanoma. J Invest Dermatol 126: 1660-1663, 2006.

28. Wilkens L, Tchinda J, Burkhardt D, Nolte M, Werner M and Georgii A: Analysis of hematologic diseases using conventional karyotyping, fluorescence in situ hybridization (FISH), and comparative genomic hybridization (CGH). Hum Pathol 29: 833-839, 1998 .

29. Eicke N, Günthert AR, Viereck V, Siebold D, Béhé M, Becker T, Emons $\mathrm{G}$ and Gründker C: GnRH-II receptor-like antigenicity in human placenta and in cancers of the human reproductive organs. Eur J Endocrinol 153: 605-612, 2005.

30. Cheskis BJ, Greger J, Cooch N, McNally C, Mclarney S, Lam HS Rutledge S, Mekonnen B, Hauze D, Nagpal S and Freedman LP: MNAR plays an important role in ER $\alpha$ activation of Src/MAPK and PI3K/Akt signaling pathways. Steroids 73: 901-905, 2008.

31. Gururaj AE, Holm C, Landberg G and Kumar R: Breast cancer-amplified sequence 3 , a target of metastasis-associated protein 1 , contributes to tamoxifen resistance in premenopausal patients with breast cancer. Cell Cycle 5: 1407-1410, 2006.

32. Kumar R, Zhang H, Holm C, Vadlamudi RK, Landberg G and Rayala SK: Extranuclear coactivator signaling confers insensitivity to tamoxifen. Clin Cancer Res 15: 4123-4130, 2009.

33. Lo TL, Yusoff P, Fong CW, Guo K, McCaw BJ, Phillips WA, Yang H, Wong ES, Leong HF, Zeng Q, Putti TC and Guy GR: The ras/mitogen-activated protein kinase pathway inhibitor and likely tumor suppressor proteins, sprouty 1 and sprouty 2 are deregulated in breast cancer. Cancer Res 64: 6127-6136, 2004.

34. Kurokawa H, Lenferink AE, Simpson JF, Pisacane PI, Sliwkowski MX, Forbes JT and Arteaga CL: Inhibition of HER 2/neu (erbB-2) and mitogen-activated protein kinases enhances tamoxifen action against HER2-overexpressing, tamoxifen-resistant breast cancer cells. Cancer Res 60: 5887-5894, 2000.

35. Massarweh S, Osborne CK, Jiang S, Wakeling AE, Rimawi M, Mohsin SK, Hilsenbeck S and Schiff R: Mechanisms of tumor regression and resistance to estrogen deprivation and fulvestrant in a model of estrogen receptor-positive, HER-2/neu-positive breast cancer. Cancer Res 66: 8266-8273, 2006.

36. Creighton CJ, Massarweh S, Huang S, Tsimelzon A, Hilsenbeck SG, Osborne CK, Shou J, Malorni L and Schiff R: Development of resistance to targeted therapies transforms the clinically associated molecular profile subtype of breast tumor xenografts. Cancer Res 68: 7493-7501, 2008.

37. Hutcheson IR, Knowlden JM, Madden TA, Barrow D, Gee JM Wakeling AE and Nicholson RI: Oestrogen receptor-mediated modulation of the EGFR/MAPK pathway in tamoxifen-resistant MCF-7 cells. Breast Cancer Res Treat 81: 81-93, 2003.

38. Arpino G, Gutierrez C, Weiss H, Rimawi M, Massarweh S, Bharwani L, De Placido S, Osborne CK and Schiff R: Treatment of human epidermal growth factor receptor 2-overexpressing breast cancer xenografts with multiagent HER-targeted therapy. J Natl Cancer Inst 99: 694-705, 2007.
39. Kondapaka SB, Singh SS, Dasmahapatra GP, Sausville EA and Roy KK: Perifosine, a novel alkylphospholipid, inhibits protein kinase B activation. Mol Cancer Ther 2: 1093-1103, 2003.

40. Knowlden JM, Jones HE, Barrow D, Gee JM, Nicholson RI and Hutcheson IR: Insulin receptor substrate-1 involvement in epidermal growth factor receptor and insulin-like growth factor receptor signalling: implication for Gefitinib ('Iressa') response and resistance. Breast Cancer Res Treat 111: 79-91, 2008.

41. Fekete M, Wittliff JL and Schally AV: Characteristics and distribution of receptors for [D-TRP6]-luteinizing hormonereleasing hormone, somatostatin, epidermal growth factor, and sex steroids in 500 biopsy samples of human breast cancer. J Clin Lab Anal 3: 137-147, 1989.

42. Baumann KH, Kiesel L, Kaufmann M, Bastert G and Runnebaum B: Characterization of binding sites for a GnRH-agonist (buserelin) in human breast cancer biopsies and their distribution in relation to tumor parameters. Breast Cancer Res Treat 25: 37-46, 1993.

43. Miller WR, Scott WN, Morris R, Fraser HM and Sharpe RM: Growth of human breast cancer cells inhibited by a luteinizing hormone-releasing hormone agonist. Nature 313: 231-233, 1985.

44. Foekens JA, Henkelman MS, Fukkink JF, Blankenstein MA and Klijn JG: Combined effects of buserelin, estradiol and tamoxifen on the growth of MCF-7 human breast cancer cells in vitro. Biochem Biophys Res Commun 140: 550-556, 1986.

45. Emons G, Ortmann O, Becker M, Irmer G, Springer B, Laun R, Hölzel F, Schulz KD and Schally AV: High affinity binding and direct antiproliferative effects of LHRH analogues in human ovarian cancer cell lines. Cancer Res 53: 5439-5446, 1993.

46. Gründker C, Schlotawa L, Viereck V, Eicke N, Horst A, Kairies B and Emons G: Antiproliferative effects of the GnRH antagonist cetrorelix and of GnRH-II on human endometrial and ovarian cancer cells are not mediated through the GnRH type I receptor. Eur J Endocrinol 151: 141-149, 2004.

47. Gründker C, Günthert AR, Millar RP and Emons G: Expression of gonadotropin-releasing hormone II (GnRH-II) receptor in human endometrial and ovarian cancer cells and effects of GnRH-II on tumor cell proliferation. J Clin Endocrinol Metab 87: 1427-1430, 2002.

48. Buchholz S, Seitz S, Schally AV, Engel JB, Rick FG, Szalontay L, Hohla F, Krishan A, Papadia A, Gaiser T, Brockhoff G, Ortmann O, Diedrich K and Köster F: Triple-negative breast cancers express receptors for luteinizing hormone-releasing hormone (LHRH) and respond to LHRH antagonist cetrorelix with growth inhibition. Int J Oncol 35: 789-796, 2009.

49. Gründker C, Fost C, Fister S, Nolte N, Günthert AR and Emons G: Gonadotropin-releasing hormone type II antagonist induces apoptosis in MCF-7 and triple-negative MDA-MB-231 human breast cancer cells in vitro and in vivo. Breast Cancer Res 12: R49, 2010.

50. Fister S, Günthert AR, Aicher B, Paulini KW, Emons G and Gründker C: GnRH-II antagonists induce apoptosis in human endometrial, ovarian, and breast cancer cells via activation of stress-induced MAPKs p38 and JNK and proapoptotic protein Bax. Cancer Res 69: 6473-6481, 2009. 